\title{
Effects of Ozone Stress on Secondary Metabolism and Antioxidant Capacity in Soybean Roots
}

\author{
Tian-hong ZHAO ${ }^{\text {a }}$, Wei WANG, Rong-rong TIAN and Yan WANG ${ }^{*}$ \\ College of agronomy, Shenyang Agricultural University, Shenyang 110866, China
}

\author{
Tel: 13940107190 \\ azth1999@163.com \\ www.syau.edu.cn \\ ${ }^{*}$ Corresponding author.
}

Keywords: Ozone Stress, Soybean Roots, Phenolic Substances, Antioxidant Metabolism.

\begin{abstract}
In this paper, to examine the effects of elevated ozone on secondary metabolism and antioxidant capacity in soybean roots, as well as reactive oxygen species and antioxidant enzymes activity. Soybean grown in open top chambers (OTCs) were exposed to ambient air $\left(\left[\mathrm{O}_{3}\right]=40 \mathrm{nmol}^{\circ} \mathrm{mol}^{-1}\right)$ and elevated ozone $\left(\left[\mathrm{O}_{3}\right]=110 \pm 10 \mathrm{nmol}^{\circ} \mathrm{mol}^{-1}\right)$. The results revealed that with ozone concentration rising, compared with control, the $\mathrm{O}_{3}$ stress induced the total flavonoids content in soybean root of all treatments showed a significant rising trend $(\mathrm{P}<0.05)$, and the total polyphenols content showed a rising trend but not significant. The PAL and PPO activity of soybean root was always lower than that of CK, the LOX activity of soybean root was always higher than that of CK, but the PAL $\square$ LOX and PPO activity of soybean root expressed an increased trend with the increase of soybean growth period. However, variation of antioxidant enzymes activity in soybean roots was very different from each other. Superoxide dismutase (SOD) activity was lower than the $\mathrm{CK}$ treatment at flowering and podding stages under elevated ozone stress, it presents a volatility changes. During the whole growth stage, elevated ozone stress induced a decrease on activity of catalase (CAT) except for flowering stage, it had a significant increase $(\mathrm{p}<0.05)$, the ozone treatment was higher than the $\mathrm{CK}$ treatment in general except flowering stage. Activity of peroxidase (POD) was increased under elevated ozone. It had a higher representation $(\mathrm{p}<0.05)$ than the $\mathrm{CK}$ treatment at every stage. It can be concluded that the ozone stress has significant effects on soybean roots, and effects on soybean roots' normal growth.
\end{abstract}

\section{Introduction}

Ozone $\left(\mathrm{O}_{3}\right)$, is one of the most important air pollutants, has increased considerably since pre-industrial times, fast consumption of the fossil fuels is mainly responsible for significant increase in the atmospheric $\mathrm{O}_{3}$ concentration, and is predicated to exceed $80 \mathrm{ppb}$ [1]. Tropospheric ozone is formed by photochemical reactions between oxides of nitrogen, $\mathrm{CO}$, methane and other volatile organic compound in the presence of sunlight. $\mathrm{O}_{3}$ concentration as an important issues, has at tracted attention of the world's scientists and the public [2].

Open top chamber (OTC) to carry out the high concentration of $\mathrm{O}_{3}$, many domestic and foreign scholars have did a lot of exploring on plant morphology, growth development and physiological and biochemical characteristics through OTC. The results show that $\mathrm{O}_{3}$ stress could inhibit the activity of protective enzymes and 
protective substances in wheat and soybean [3], and that drought and salinity stress can relatively promote root reducing strength and nitrate reductase activity [4].

Containing rich protein and other high-quality nutrients, soybean is not only one old crop, but one of the global five main crops. The past researches of root mostly happened on nutrient press, water stress and salinity stress, as for $\mathrm{O}_{3}$ stress, the results as follow: $\mathrm{O}_{3}$ treatment could produce negative effect of reducing carbon distribution for root [5]. This experiment took soybean roots as the test material, researching secondary metabolism and antioxidant enzymes activity to provide correlation evidences.

\section{Materials and Methods}

\section{Plant Materials}

Soybean (Glycine Max.) cultivars "iron 29" as the test materials, and this experiment was started at May to September in 2010 at the national field research station of Shenyang agroecosystems, Liaoning.

\section{Experime ntal Design}

This experiment was used open top chambers (OTCs) to realize $\mathrm{O}_{3}$ stress of soybean processing. Ozone was generated by ozone generator (GP - $5 \mathrm{j}$, China) and ozone sensor (S-900, New Zealand), and the $\mathrm{O}_{3}$ concentrations was controlled by computers, and used automatic pneumatic system to analyses the date. This test set CK (control of air chamber, $\mathrm{O}_{3}$ concentrations of about 40 nmol.mol-1) and $\mathrm{O}_{3}$ (elevated $\mathrm{O}_{3}$ concentration, compared to $110+10 \mathrm{nmol} \cdot \mathrm{mol}-1$ ) two processing. Each processing set three times repeated. On May 20, sowing seeds, soybeans emergence after 20 days began to ozone stress, in total 9 hours (8:00 am to 17:00 PM), soy branching period (July 6) respectively, flowering period (August 1) and podding period (23 August), soybean stop stress treatment when mature. Rinse after each sampling root, select of soybean root parts same as the test materials, determination of related indicators.

\section{Indicators and Measuring Method}

Total flavonoids $\square$ the total polyphenol $\square$ lipoxygenase (LOX) and polyphenol oxidase (PPO) activity was assayed by Kong [6]; henylalanine ammonia lyase (PAL) activity was measured by Li [7], SOD $\square$ CAT and POD activity was assayed by ultraviolet absorption method [8].

All date were subjected to statistical analyzed by one-way analysis of variance using SPSS 22.0 and Microsoft Excel 2003 software. Significance was fixed at the 0.05 level throughout the study.

\section{Results}

\section{The Flavonoids and Poly phenols Content in Soybean Roots under Ozone Stress}

From the Fig.1, with the soybean growing period, the total flavonoids content (1) and the total polyphenols content (2) in soybean root of all treatments showed a rising trend, and presented $\mathrm{CK}<\mathrm{O}_{3}$. The content of total flavonoids reached significant in podding stage $(\mathrm{P}<0.05)$, and in the remaining two period is not significant. But the content of total flavonoids not reached significant in all stages. 


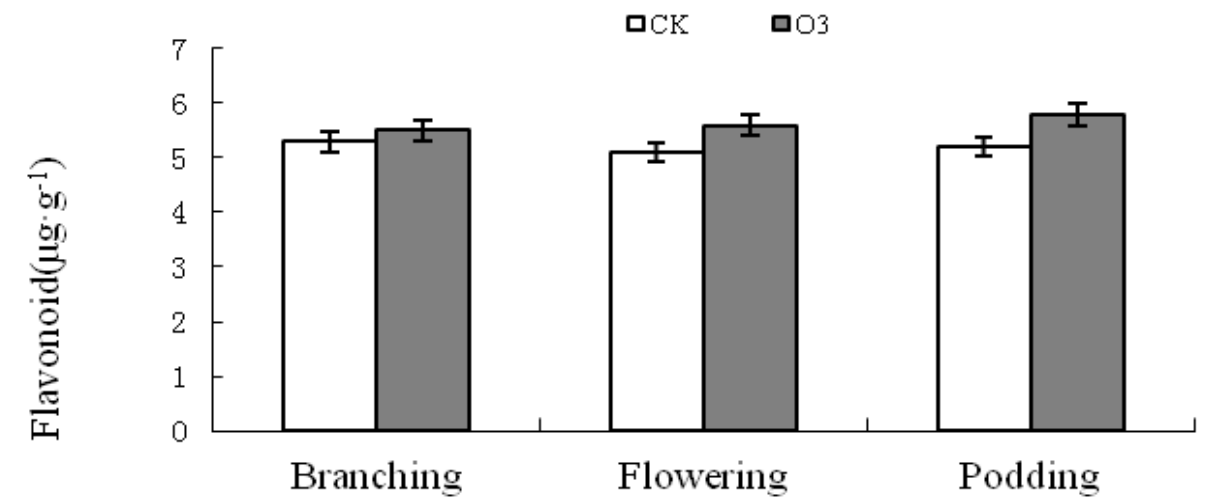

(1)

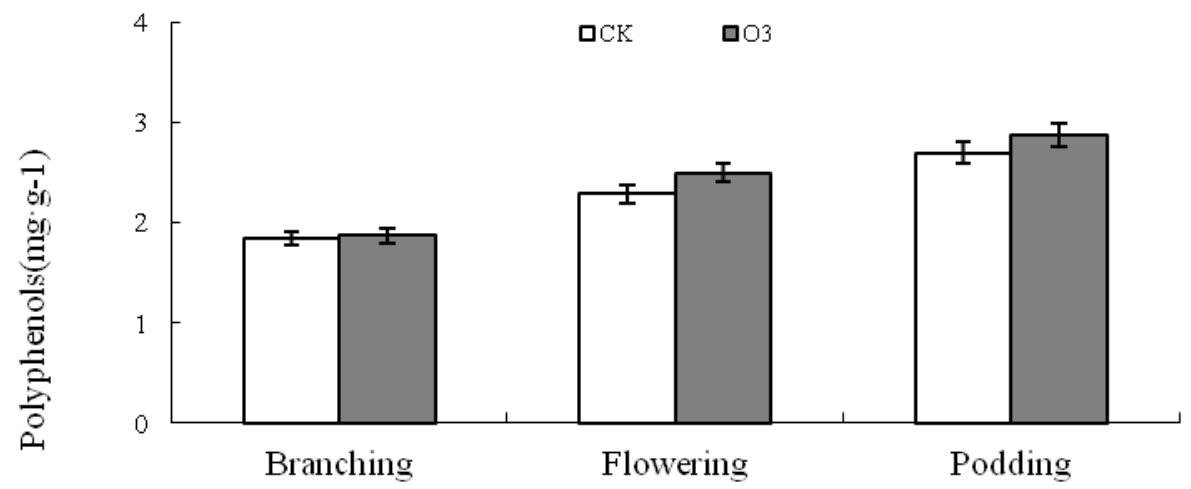

(2)

Figure 1 Variation of flavonoids and polyphenols content in soybean roots under ozone stress

\section{The PAL $\square$ LOX and PPO Activity of Soybean Root under Ozone Stress}

Fig. 2 results showed that the PAL(1) $\square \mathrm{LOX}(2)$ and $\mathrm{PPO}(3)$ activity of soybean roots expressed an increased trend with the increase of soybean growth period. Compared with the control, the PAL and PPO activity of soybean root was always lower than $\mathrm{CK}$, and the expression was $\mathrm{CK}>\mathrm{O}_{3}$, and reached significant in all stages $(\mathrm{P}<0.05)$. But the LOX activity of soybean root was always higher than $\mathrm{CK}$, and the expression was $\mathrm{CK}<\mathrm{O}_{3}$.

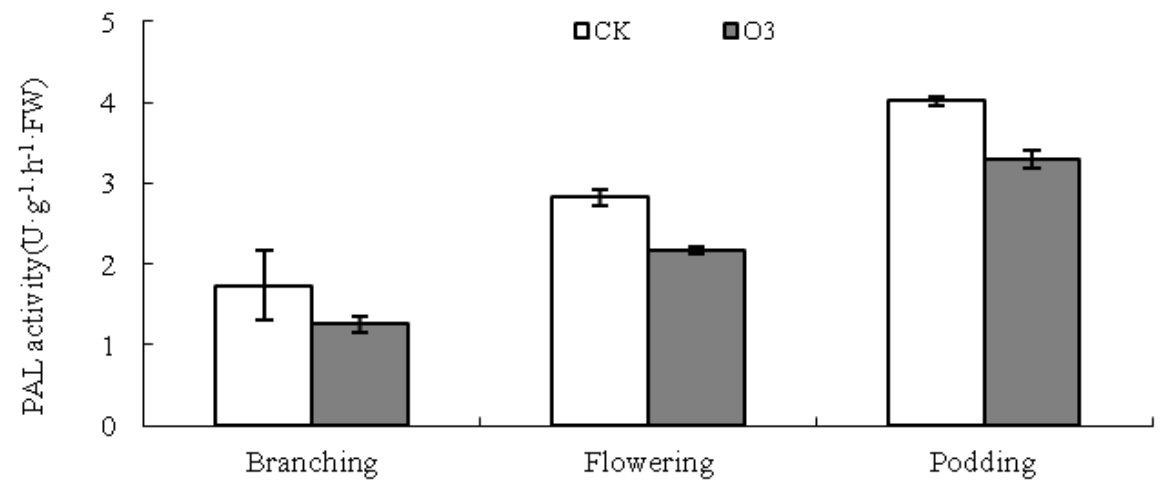

(1) 


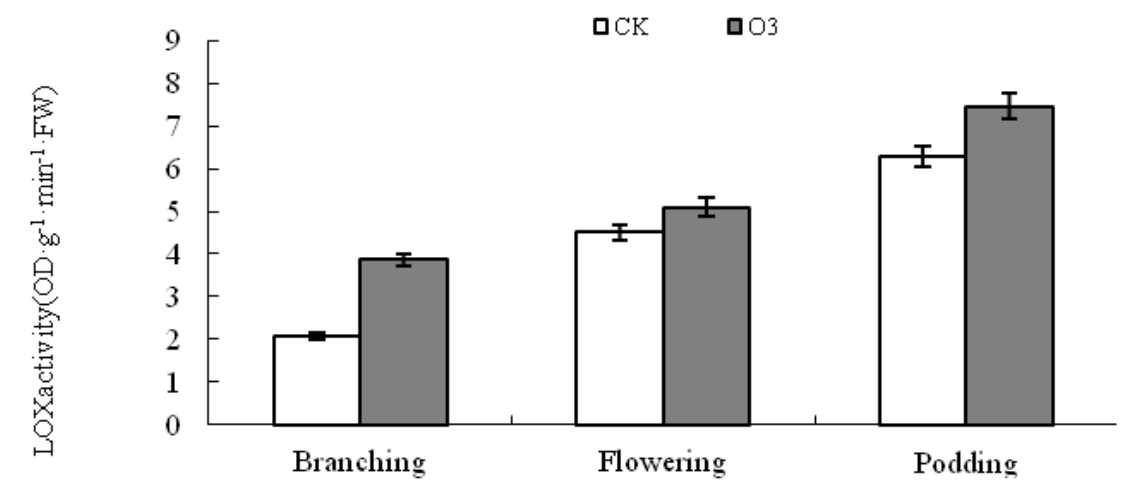

(2)

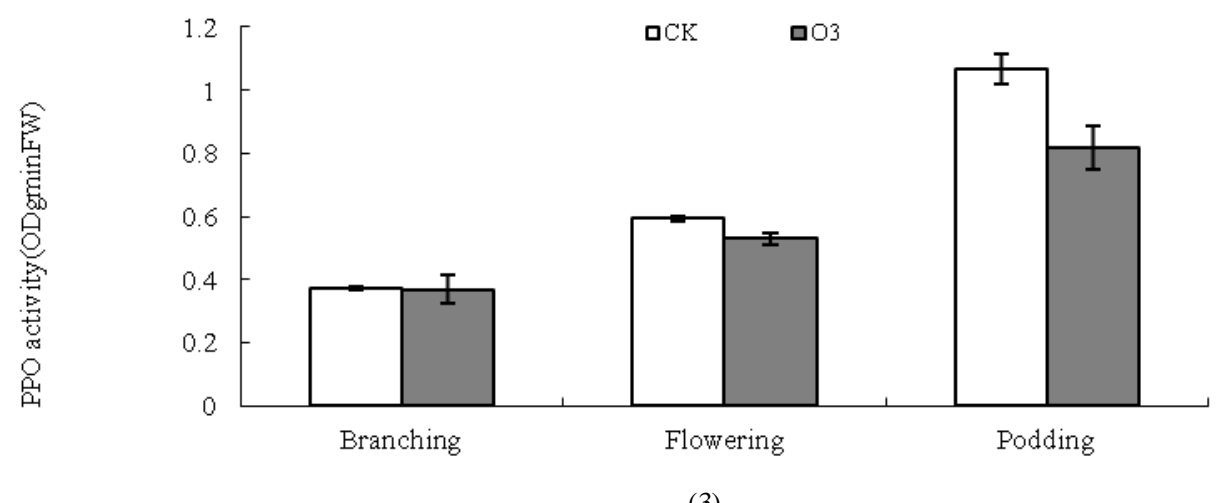

(3)

Figure. 2 Variation of PAL, LOX and PPO activity in soybean roots under ozone stress

\section{The Antioxidant Enzymes Enzy me Activity of Soybean Root under Ozone Stress}

Fig. 3 (1) reveals SOD activity had volatility of early increase and late decrease in general in the whole growth. These results show that $\mathrm{O}_{3}$ stress has boosted SOD activity in a short run, but would damage the plant cell and devitalize the SOD as the stress extended. Under the $\mathrm{O}_{3}$ stress (Fig. 3(2)), while in flowering CAT activity was lower than CK treatment, yet in the other two stages higher than the latter, especially in the podding stage, and reach significant level $(\mathrm{P}<0.05)$. Fig. 3 (3) reveals POD activity a volatility of early increased. Each stage witnessed a POD activity of $\mathrm{O}_{3}$ treatment than that of $\mathrm{CK}$ treatment, especially in the podding stage, and reach significant level $(\mathrm{P}<0.05)$.

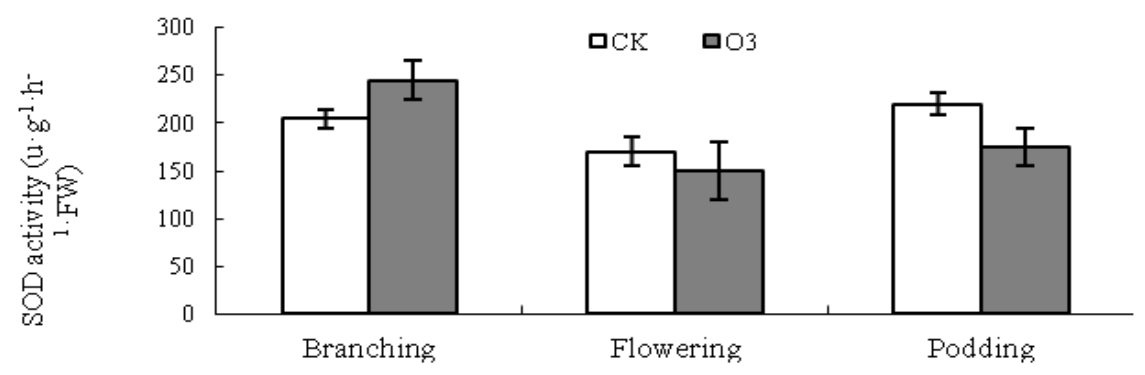

(1) 


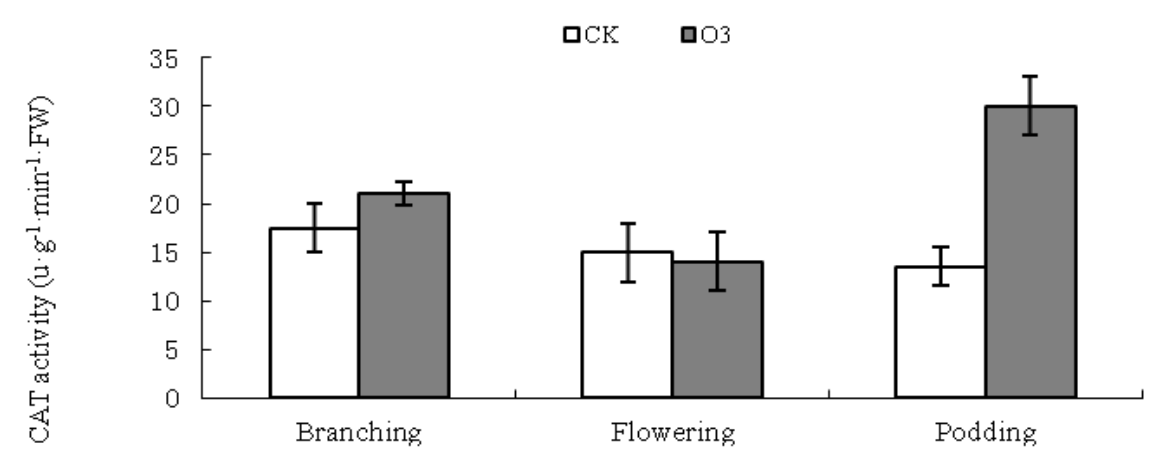

(2)

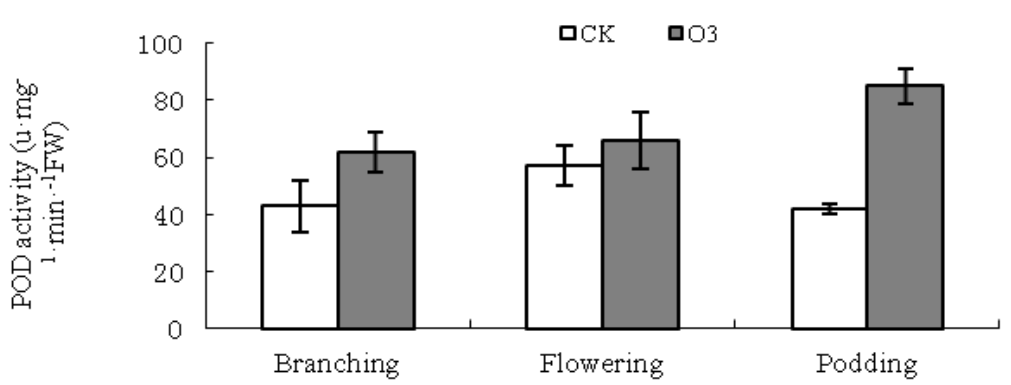

(3)

Figure. 3 Variation of SOD $\square \mathrm{POD}$ and CAT activity in soybean roots under ozone stress

\section{Discussion}

Phenylalanine ammonia lyase (PAL) is an important enzyme of plant secondary metabolism process, and make up a key enzyme in phenylpropanoid metabolism and enzyme [9]. $\mathrm{O}_{3}$ stress had a certain influence on total polyphenols content of soybean roots. The metabolism of phenolic compounds in plants is regulated by polyphenol oxidase (PPO), which is a direct result of the oxidation of phenolic compounds. In this experiment, the PAL and PPO activity of soybean roots expressed an upward trend under the condition of $\mathrm{O}_{3}$, and reached the highest at podding stage, and the content of total flavonoids and total polyphenols content also reached the peak in pod period, which proves that the level of PAL activity can reflect the formation rate of the total flavonoids in size, those all related to the $\mathrm{O}_{3}$ stress. The antioxidant activity of phenolic compounds is one of the important ways to defend the $\mathrm{O}_{3}$ damage, it is mainly manifested in two aspects: the generation of free radicals and the elimination of free radicals. The present study showed that with the increase of $\mathrm{O}_{3}$ concentration, the activity of LOX was increased, it was show that the concentration of ozone stress could induce the increase of total flavonoids and total polyphenols in soybean roots, which was consisted with the results of Valencia-Islas [10].

In its long evolution, plant has developed an integral defense system that will be activated to protect its cells from injury of reactive oxygen when it is invaded from outside. SOD, CAT and POD are main ones of the antioxidant enzymes within the plant. $\mathrm{O}_{2}-$ can be developed to be $\mathrm{O}_{2}$ and $\mathrm{H}_{2} \mathrm{O}_{2}$ by SOD that plays a core role in the protective enzymes system, for it is the only antioxidant enzyme which can reduce $\mathrm{O}_{2}{ }^{-}$to be $\mathrm{H}_{2} \mathrm{O}_{2}$ and oxidize it to be $\mathrm{O}_{2}$. In the study, SOD activity was higher than CK first then lower than $\mathrm{CK}$. In the study of $\mathrm{O}_{3}$ effects upon winter wheat leaf, we have found that SOD activity would firstly increase at a low concentration of $\mathrm{O}_{3}$, and then had a slump[11]. High concentration of $\mathrm{O}_{3}(150 \mathrm{nmol} \cdot \mathrm{mol}-1)$ wholly resulted in a bit 
higher SOD activity than that of CK treatment[12].So the O3 stress has the ability of restraining SOD activity in root cells and damaging the antioxidation system. CAT is crucial to remove $\mathrm{H}_{2} \mathrm{O}_{2}$ within $\mathrm{C}_{3}$ plant and has ability to catalyz $\mathrm{H}_{2} \mathrm{O}_{2}$ into $\mathrm{H}_{2} \mathrm{O}$; and POD mainly functions as catalyst of $\mathrm{H}_{2} \mathrm{O}_{2}$ and organic peroxide. In the experiment, $\mathrm{O}_{3}$ stress heightened CAT and POD activity of soybean root, we could find that CAT and POD increased, and removed redundant reactive oxygen protecting the cells from injury. Two different mechanisms of peroxide enzymes exist with in plant: one will turn out to be protective when the plant suffers the early stage of adversities and aging, and the other can be harmful when the plant undergoes the late stage of adversities and aging[13]. The inconsistent results perhaps came from different protective enzyme mechanisms in plant, and in the experiment, it turned to be protective when the activity of POD increased.

\section{Acknowledgme nts}

Work supported by grant 31570404 and 30970448 of the China National Natural Science Foundation

\section{Reference}

[1] $\mathrm{S} \mathrm{Xu}, \mathrm{XY} \mathrm{He}, \mathrm{W}$ Chen, et al. Differential sensitivity of four urban tree species to ele vated O3. Urban Forestry \& Urban Greening, 14: 1166-1173 (2015).

[2] K Sumita K, Madhoolike A, Aradhana S. Effects of ambient and elevated CO and ozone on physiological characteristics, antioxidative defense system and metabolites of potato in relation to ozone flux. Environmental and Experimental Botany, 276-287 (2015).

[3] T H Zhao, J W Sun, Y Fu, et al. Effects of elevated CO2and O3 concentration on active oxygen metabolism and anti-oxidative enzymes activities in spring wheat. Scientia Agricultura Sinica, 42(1):64-71 (2009).

[4] Sechenbater and H Y Wu, Effect of different stress on roots activity and nitrate reductase activity in Zea mays L,Agricultural Research in the Arid Areas, 19,67-70(2001).

[5] D F Karnosky, K S Pregitzer, D R Zak, et al. Scaling ozone responses of forest trees to the ecosystem level in a changing climate. Plant, Cell and Environment, (28):965- 981 (2005).

[6] X S Kong, X F Yi. Experimental Manual on Plant Physiology. Beijing: Chinese Agriculture Press, 124-270 (2008).

[7] X H Li, J H Huang, Y Wang, et al. Relationships between secondary metabolites DIMBOA content and phenylalanine ammonialyase(PAL) activity in maize. Journal of Anhui Agricultural Science, 36(11): 4726-4727 (2008).

[8] L Li. Plant Physiology Module Experiment Guide. Bei-jing: Science Press, (2009).

[9] A Wahid, and A Ghazanfar. Possible involvement of some secondary metabolites in salt tolerance of sugarcane. Journal of Plant Physiology, 163:723-730 (2006).

[10] N Valencia-Islas, A Zambrano, J L Rojas. Ozone reactivity and free radical scavenging behavior of phenolic secondary metabolites in lichens exposed to chronic 
oxidant air pollution from Mexico city. Journal of Chemistry Ecology, 33:1619-1634 (2007).

[11] Q W Zheng, X K Wang, Z Z Feng et al. Ozone effects on chlorophyll content and lipid peroxidation in the situ leaves of winter wheat. Acta botanica boreali-occidentalia sinica 25,2240-2244(2005).

[12] W W Zhang, F X Zheng, X K Wang, et al, Effects of ozone on root activity, soluble protein content and antioxidant system in Oryza sative roots, Chinese Journal of Plant Ecology 33(2009) 425-432.

[13] S L Guo, F Fang, S Qiang. Influences of temperature on physiological indices of seven exotic weeds and their adaptive significance. Guihaia,23(1):73-76 (2003) 